\title{
Fighting Behaviour of Male Onion Thrips, Thrips tabaci (Thysanoptera: Thripidae) Lineages
}

\author{
W. A. WOLDEMELAK \\ Department of Entomology, Faculty of Horticultural Sciences, Szent István University, \\ H-1118 Budapest, Villányi út 29-43, Hungary
}

(Received: 28 January 2020; accepted: 6 April 2020)

\begin{abstract}
Onion thrips, Thrips tabaci Lindeman, 1889 (Thysanoptera: Thripidae) has three distinctive reproductive modes: arrhenotokous, thelytokous and deuterotokous. This experiment was focused on the arrhenotokous leek-(L1) and tobacco-associated (T) T. tabaci lineages. These two lineages are distinctively varied genetically and in host adaptations. L1 and T lineages perform better on leek and tobacco plants, respectively. Fighting occurs between males when they compete for food, mating, and oviposition sites. The aim of this research was to examine the fighting behaviour and characterize the fighting elements of males in L1 and T lineages. The experiment was performed in the laboratory by using a Euromex VC.3036 video camera and each experiment was recorded for a duration of 10 minutes. Transparent PCR tube caps formed the arena to observe the fighting interactions in both lineages. A total of 40 video recordings have been observed and each recording had a different arena. The fighting performance was observed at 2, 5, 8, 10, 12 days old specimens in four replications. This result has shown L1 lineage had better fighting performance and a more aggressive fighting ability than $\mathrm{T}$ lineage. Antennal bouts, jumping, flipping, stabbing and pitching are the most commonly observed fighting elements.
\end{abstract}

Keywords: Arrhenotoky, behaviour, interaction, lineage, Thrips tabaci, video.

Fighting occurs between males of many insect species when competing for food (Blanckenhorn, 1991), mating (West et al., 2001), oviposition site (Moore and Greeff, 2003), keeping territory (Kemp and Alcock, 2003) and egg guarding (Crespi, 1992). Fighting between two opponents results in either victory or loss (Chase et al., 1994). The winner often dominates the competed resources. Occasionally, severe fighting leads to death in some insect species (Crespi, 1992). A number of factors determine the intensity of fighting as well as the outcome of fights between contestants such as body size and morphology (males with enlarged forelegs, tarsal claws, and large forehead win the contests), and fighting experience (Mound, 1991; Reaney et al., 2011; Terry and Dyreson, 1996). Individual fighting performance is often influenced by the outcomes of their previous contests (Rutte et al., 2006). A competing individual with victorious experience has a chance to win the next encounter as well (Rutte et al., 2006), and an individual with a recent history of losing is likely to lose the next encounter again and eventually leave the resources (Chase et al., 1994).

Male fighting behaviour has been observed in members of the Tubulifera suborder such as in Hoplothrips karnyi (Hood) (Crespi, 1988a), Elaphrothrips tuberculatus (Hood)

*E-mail: atilaw12@gmail.com 
(Crespi, 1986a), Hoplothrips pedicularius (Haliday) (Crespi, 1986b), Kladothrips rugosus (Froggatt), Oncothrips tepperi (Karny), Onychothrips tepperi (Karny), Csirothrips watsoni (Mound), Thaumatothrips froggatti (Karny) and Phallothrips houstoni (Crespi, 1992). Fights in these thrips species are presumably associated with mating, food, and egg guarding.

However, fighting is not limited to occur only in members of the Tubulifera suborder since there are a few studies reporting of male fighting behaviour in members of the Terebrantia suborder thrips species such as in Frankliniella occidentalis (Pergande) (Olaniran and Kirk, 2012; Terry and Gardner, 1990) and Frankliniella intonsa (Trybom) (Kirk, 1996). F. occidentalis males form an aggregation in which two or more males occupy one place. During this aggregation, aggressive fighting interactions between males were observed. In insect species, mating and fighting interactions are initiated by chemical cues produced by the males such as male-specific cuticular hydrocarbons and aggregation pheromones (Olaniran et al., 2013).

The genetic variability of onion thrips confirmed that $T$. tabaci has three distinctive lineages based on sequence differences of a portion of the mitochondrial Cytochrome-c Oxidase subunit I (COI) gene: two leek-(L1 and L2) and one tobacco-associated (T) lineages (Lewis, 1973; Jenser and Szenasi, 2004). L1 and T lineages have arrhenotokous and L2 lineage has thelytokous mode of reproduction. Deuterotoky, the reproductive mode where unfertilized eggs yield both males and females, has been reported in T. tabaci. This study focuses on the two arrhenotokous (L1 and T) lineages. Male fighting behaviour, and the importance of male-produced sex pheromones have been studied in F. occidentalis but have been neglected in T. tabaci lineages.

The aim of this paper was to characterize and detect elements of fighting behaviour of male in L1 and T lineages.

\section{Materials and Methods}

\section{Thrips rearing}

To initiate the experiment, twenty female adults of unknown age were isolated from the stock colonies of each lineage and reared individually in $2 \mathrm{ml}$ microcentrifuge tubes on leaf discs of their preferable host plant. L1 females were given cabbage and T female's tobacco. To ensure the production of ample male progeny for the experiment, these adult females were transferred to new tubes daily until their death. Then the females were preserved in $96 \%$ ethanol individually until the lineage was confirmed based on sequences of a mitochondrial COI (mt COI) product (Farkas et al., 2019). The newly hatched first instar larvae were individually transferred to new microcentrifuge tubes and kept at $23{ }^{\circ} \mathrm{C}$ under a long photoperiod (16L: 8D). Upon reaching maturity, adult males were collected daily for the purposes of the experiment. These males were isolated and kept individually in a separate micro-centrifuge tube. This way ensured that no males had ever had any contact with other males. 


\section{Bioassay}

Arena technique as described by Kirk (1987) was adapted for this experiment. Transparent PCR tube caps were used to form the arena. A total of 80 males ( 40 belonged to L1 and 40 belonged to T lineages) were used for this experiment, and the pairs of males were $2,5,8,10,12$ days old in four replications. Two males with no previous fighting experience were transferred into the PCR tube cap, and a microscopic glass coverslip was immediately sealed onto the PCR tube caps to form the roof of the arena and this way used to prevent males from escaping.

\section{Video recording}

A Euromex VC.3036 video camera was placed above the arena on a stereomicroscope at a height of $15 \mathrm{~cm}$ that enabled to view the whole arena. This was connected to a video recorder hp computer and each experiment was recorded with a resolution of $1920 \times 1080$ for a duration of $10 \mathrm{~min}$. Data were obtained from the recorded video. Each recording had a different arena.

\section{Observations}

A total of 40 video recordings (20-20 for L1 and T, with 40 individuals for each lineages) were observed. Fighting was defined as observations of contact between two males with antennal bouts, abdominal flicking, grabbing and flipping, where these actions took more than 1 second. The percentage of fighting males, fighting frequency (number of fights recorded in the arena during the observation period), pre-fight period (the time before the first fight), duration of fight and re-fighting time interval (the time between two consecutive fights) were recorded during each 10-minute observation.

\section{Statistical analyses}

All statistical analyses were performed using SPSS software (IBM Inc, Chicago, IL, USA). Ages were used as a block factor to eliminate its source of variability on the general fighting performance of the lineages (Gomez and Gomez, 1984). Means of fighting frequency, pre-fight period, duration of fight and of refighting time interval were analysed separately using GLM of multivariate analysis of variance to test the mean differences between the lineages. All means have been given with their standard deviations. All the parameters were transformed by natural logarithm $(\ln (\mathrm{x}))$ functions. The normality of the residuals was confirmed by using nonparametric Kolmogorov-Smirnov and Shapiro-Wilk tests $(\mathrm{P}>0.05)$. The Games-Howell post hoc test was used to compare the significant difference of the variables. 


\section{Results}

\section{Behavioural patterns observed during fighting}

Aggressive fighting interactions occurred in the small arena with different fighting movements. When the two contestants approached each other, they first contacted with their moveable antennae, and then chased each other around the arena. Occasionally, the contestants stopped to vibrate their wings and rub their hind legs. Antennal bouts (Fig 1a), jumping (Fig 1b) flipping, stabbing and pitching (Fig 1c) are the most commonly observed fighting movements. Fights often ranged from few initial abdominal bouts, antennal flicking to escalated aggressive interactions. Several prolonged fights with stabbing and pitching beyond the less aggressive abdominal and antennal bouts, abdominal flipping and flicking, were observed.

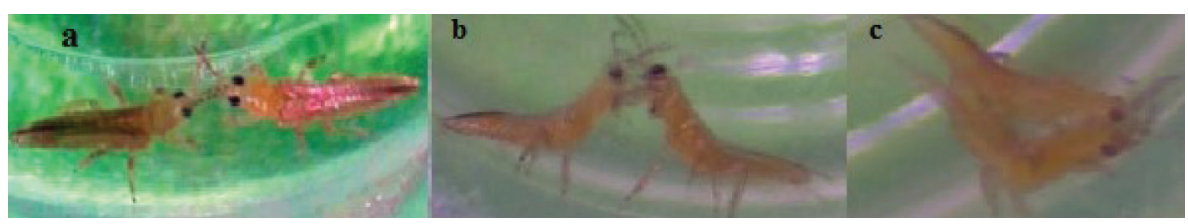

Fig. 1 The most frequent fighting movements observed between males of L1 and T lineages of the onion thrips in a laboratory experiment: (a) antennal bouts, (b) jumping, and (c) stabbing and pitching fighting tactics

In this experiment, similar fighting movements were observed in L1 and T males: (1) Parallel abdominal bouts: the males lining up in side-to-side and flicking abdomens at each other. (2) Antennal bouts: the males approached each other and rapidly vibrated their antennae up and down until they made antennal contact. The antennal contacts ranged from a rhythmic, but calm movement to rapid movements. (3) Stabbing and pitching: where one male climbed onto the back of the other male and grasped the contestant with its forelegs. (4) Flipping: where a male quickly lifted its abdomen directly into the air. Flipping of the abdomen may be used as a defensive strategy. (5) Jumping: where both males lifted their thorax and flipped forelegs toward the head of their opponent to grasp each other.

\section{Fighting performance}

The video recordings showed that while $100 \%$ of the tested L1 males fought and had more aggressive interactions, only $50 \%$ of the tested T males fought. Fights between males of $\mathrm{T}$ lineage were less frequent and calmer (Fig 2).

\section{Fighting frequency, pre-fight period, duration of fight and refighting time interval}

No significant differences were found in the fighting frequencies, pre-fight periods, durations of fights and refighting time intervals. $\mathrm{F}(1: 22)=4.049 ; \mathrm{P}>0.05, \mathrm{~F}(1: 22)=1.861$; $\mathrm{P}>0.05, \mathrm{~F}(1,22)=3.296 ; \mathrm{P}>0.05, \mathrm{~F}(1,22)=0.046 ; \mathrm{P}>0.05$ (Table 1). Duration of fight was longer between members of the L1 lineage than those of the T lineage. L1 males have shown immediate mobility and were more active throughout the experiment. 


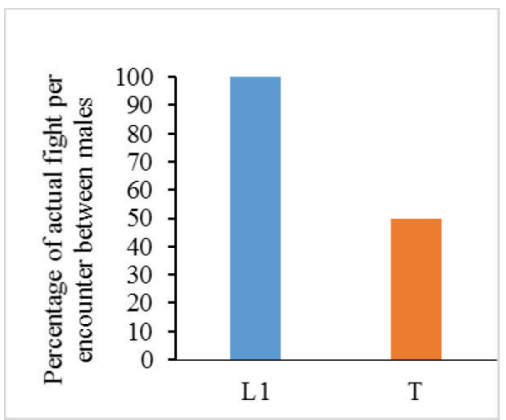

Fig. 2 Comparison of actual fights per encounter between males of $\mathrm{L} 1$ and $\mathrm{T}$ lineages of the onion thrips in a laboratory experiment

Table 1

The rate of fighting interactions including fighting frequency (number of fights recorded in the arena during the observation period), pre-fight period (the time before the first fight in seconds), duration of fight (in seconds) and re-fighting time interval (the time between two consecutive fights, in seconds) between males of L1 and T lineages of the onion thrips in a laboratory experiment during 10-minute observations in the arena (mean $\pm \mathrm{Std})(\mathrm{n}=20$ in L1 and 20 in $\mathrm{T})$

\begin{tabular}{lcc}
\hline & L1 & $T$ \\
\hline Fighting frequency & $4.25 \pm 2.7 \mathrm{a}$ & $2.45 \pm 3.24 \mathrm{a}$ \\
Pre-fight period $(\mathrm{sec})$ & $84.90 \pm 167.05 \mathrm{a}$ & $191.91 \pm 213.61 \mathrm{a}$ \\
Duration of fight $(\mathrm{sec})$ & $7.45 \pm 8.05 \mathrm{a}$ & $3.55 \pm 2.62 \mathrm{a}$ \\
Refighting time interval $(\mathrm{sec})$ & $120.00 \pm 120.58 \mathrm{a}$ & $193.73 \pm 207.63 \mathrm{a}$ \\
\hline
\end{tabular}

Similar lower-case letters indicate no significant difference at $\mathrm{p}>0.05$.

\section{Discussion}

Aggressive fighting interactions occurred in the small arena with different fighting movements. Parallel abdominal bouts, antennal bouts, flipping, stabbing, and jumping were the most frequent fighting movements in both L1 and T lineages. These movements can be considered assessments: this is how an individual may determine the body size and fighting ability of its opponent to decide whether to continue or stop fighting. Smith (1982) found that assessment occurs when the success of a future fight between opponents is perceived low in the first phase of the interaction. Assessments usually settle the fights without escalation. Assessments of fighting abilities between the opponents were reported in E. tuberculatus and Hoplothrips karnyi (Crespi, 1988a). E. tuberculatus males assess the size of their opponent in two stages: during the initial approach and the initial parallel bout. The outcomes of assessments between males in fights is that the greater male chases the smaller one until it flees rather than getting engaged in the fight (Crespi, 1986a). For the decision to flee, insects are thought to assess information from agonistic signals exchanged during the fighting (Stevenson and Rillich, 2012). Individuals of certain insect species assess their own fighting ability, and not that of their opponent. This is the case in honeybees (Dietemann et al. 2008). Self-assessment can occur during a contest, and an individual may decide to retreat when the costs imposed by the opponent reaches a certain threshold (Taylor and Elwood, 2003). Therefore, self-assessment during the fight may inform the 
individual that his opponent is weak and does not represent a threat to the resource. Indeed, for weak contestants that do not have information about the fighting ability of their opponents, the highest survival chance is given by not initiating a contest (Payne, 1998).

Fighting causes a lethal effect in H. karnyi, K. rugosus, O. tepperi, Koptothrips flavicornis and E. tuberculatus (Crespi, 1992, 1988a, 1988b, 1986a). Lethal fighting occurs between contestants due to the presence of enlarged forelegs, and large fore tarsal claws, which both give individuals an advantage over their less well-endowed opponents (Mound, 1991). Those physical structures are much smaller in members of the Terebrantia thrips species than in members of the Tubulifera thrips species. Although there were no immediate lethal fights in L1 and T lineages, fighting may cause long-run risks for their total longevity. Fighting males also lose time and energy that might be used searching for females (Terry, 1995). In this experiment, both lineages showed different fighting performance. L1 males exhibited more frequent fighting as $100 \%$ of them fought, whereas $\mathrm{T}$ males fight less frequently. By contrast, the L1 males had longer duration of fight, shorter prefight period, and refighting interval than T males. The difference between fighting in the two lineages is likely due to the variation in type and quantity of male-produced pheromones. Males interact over extended periods, so a pheromone may be involved as were found with males of sandfly, F. occidentalis, F. intonsa, M. sjostedti (Trybom) and T. palmi (Karny) (Akella et al., 2014; Hamilton et al., 2005; Jones and Hamilton, 1998; Kirk, 2017; Niassy et al., 2019; Zhang et al., 2011). It has been reported that a male F. occidentalis produces pheromone during aggregation. Furthermore, it has been noted in the Australian field cricket that male dominance status is associated with the expression of male pheromone signals (Thomas and Simmons, 2009). Akinyemi and Kirk (2019) found that an antiaphrodisiac pheromone was produced in $F$. occidentalis males but not in females. Thus, as L1 and T lineages have substantial variations genetically and in host adaptations, the type and quantity of male-produced pheromones may be varied too, and it may be the reason behind variations in the intensity of male fighting performance observed.

In addition, the reason behind the different fighting behaviours of the two lineages might be the body size difference between the fighter and non-fighter males in these lineages. Terry and Dyreson (1996) observed that in F. occidentalis males with wider abdomens and larger legs tend to be more aggressive during fighting and frequently engage in fights. The authors explain that a stouter abdomen gives more torque for offensive movements (such as flicking the opponent) and increased momentum of inertia for defensive movements. In addition, larger legs increase the ability to grab the opponent.

It is not clear what males gain from fighting in the absence of females and foods in the arena. Terry and Gardner (1990) suggested that males might be defending a space. Males with proportionately larger weaponry initiate fights in Gryllus pennsylvanicus (Burmeister) (Judge and Bonanno, 2008). Large males of the dew drop spider, Argyrodes antipodiana are more likely to induce fight than small males of the same species (Whitehouse, 1997). It is possible that chemical signalling controls fighting. Male-specific cuticular hydrocarbons and male-produced pheromones play a vital role in communication, particularly in mating and fighting. However, these chemicals have not been studied in T. tabaci lineages. These two lineages have shown different fighting performances, and it might be due to their body size differences. Thus, the body size, type and amount of male-specific cuticular hydrocarbons and male-produced aggregation pheromones in L1 and $\mathrm{T}$ lineages need further studies. 


\section{Acknowledgement}

I would like to express my gratitude to Dr. József Fail who provided me guidance during this experiment, and my special thanks would pass to Dr. Ladányi Márta for helping me in data analysing.

This study was financially supported by Stipendium Hungaricum Scholarship Programme (Tempus Public foundation).

\section{Literature}

Akella, S. V., Kirk, W. D., Lu, Y., Murai, T., Walters, K. F. and Hamilton, J. G. (2014): Identification of the aggregation pheromone of the melon thrips, Thrips palmi. PloS ONE, 9, e103315.

Akinyemi, A. O. and Kirk, W. D. J. (2019): Experienced males recognise and avoid mating with non-virgin females in the western flower thrips. PLoS ONE, 14(10), e0224115.

Blanckenhorn, W. (1991): Fitness consequences of food-based territoriality in water striders, Gerris remigis. Anim. Behav. 42, 147-149.

Chase, I., Bartolomeo, C. and Dugatkin, L. (1994): Aggressive interactions and inter-contest interval: how long do winners keep winning? Anim. Behav. 48, 393-400

Crespi, B. J. (1986a): Size assessment and alternative fighting tactics in Elaphrothrips tuberculatus (Insecta: Thysanoptera). Anim. Behav. 34, 1324-1335.

Crespi, B. J. (1986b): Territoriality and fighting in a colonial thrips, Hoplothrips pedicularius, and sexual dimorphism in Thysanoptera. Ecol. Entomol. 11, 119-130.

Crespi B. J. (1988a): Risks and benefits of lethal male fighting in the colonial, polygynous thrips Hoplothrips karnyi (Insecta: Thysanoptera). Behav. Ecol. Sociobiol. 22, 293-301.

Crespi, B. J. (1988b): Alternative male mating tactics in thrips: Effects of sex ratio variation and body size. Ame. Midland Natu. 119, 83.

Crespi, B. J. (1992): Behavioural ecology of Australian gall thrips (Insecta: Thysanoptera). J. Natur. Hist. 26, 769-809.

Dietemann, V., Zheng, H. Q., Hepburn, C., Hepburn, H. R., Jin, S. H., Crewe, R. M. and Pirk, C. W. (2008): Self-assessment in insects: honeybee queens know their own strength. PLoS One 3, 1-2.

Farkas, P., György, Z., Tóth, A., Sojnóczki, A. and Fail, J. (2019): A simple molecular identification method of the Thrips tabaci (Thysanoptera: Thripidae) cryptic species complex. Bulletin of Entomological Research, 1-9.

Gomez, K. A. and Gomez, A. A (1984): Statistical procedures for agricultural research (3 $\left.{ }^{\text {rd }}\right)$ ed. A Wiley-intersclence Publication John Wiley and Sons, New York, pp. 20-22.

Hamilton, J. G., Hall, D. R. and Kirk, W. D. (2005): Identification of a male-produced aggregation pheromone in the western flower thrips Frankliniella occidentalis. J. Chem. Ecol. 31, 1369-1379.

Jenser, G. and Szenasi, A. (2004): Review of the biology and vector capability of Thrips tabaci Lindeman (Thysanoptera: Thripidae). Acta Phytopathol. et Entomol. Hung., 39, 137-155.

Jones, T. M., and Hamilton, J. G. C. (1998): A role for pheromones in mate choice in a lekking sandfly. Animal behaviour, 56, 891-898.

Judge, K. A., and Bonanno, V. L. (2008): Male weaponry in a fighting cricket. PLoS one, 3 (12).

Kemp, D. and Alcock, J. (2003): Lifetime resource utilization, flight physiology, and the evolution of contest competition in territorial insects. The American Naturalist 162, 290-301.

Kirk, W. D. J. (1987): How much pollen can thrips destroy? Ecological Entomol. 12, 31-40.

Kirk, W. D. J. (1996): Thrips. Naturalist'Handbooks 25. Richmond Publishing Co. Ltd., Slough, England, 70 p.

Kirk, W. D. J. (2017): The aggregation pheromones of thrips (Thysanoptera) and their potential for pest management. International J. Trop. Insect. Sci. 37, 41-49.

Lewis, T. (1973): Thrips. Their Biology, Ecology and Economic Importance. Academic Press Inc. London, New York, 36-50.

Moore, J. and Greeff, J. (2003): Resource defence in female pollinating fig wasps: two's a contest, three's a crowd. Anim. Behav. 66, 1101-1107. 
Mound, L. (1991): Secondary sexual character variation in male Actinothrips species (Insecta: Thysanoptera), and its probable significance in fighting behaviour. J. Natur. Hist. 25, 933-943.

Niassy, S., Tamiru, A., Hamilton, J. G., Kirk, W. D., Mumm, R., Sims, C., De Kogel, W. J., Ekesi, S., Maniania, N. K. and Bandi, K. (2019): Characterization of male-produced aggregation pheromone of the bean flower thrips Megalurothrips sjostedti (Thysanoptera: Thripidae). J. Chem. Ecol. 45, 348-355.

Olaniran, O. A. and Kirk, W. D. J. (2012) Fighting behaviour of male western flower thrips, Frankliniella occidentalis (Pergande). Acta Phytopathol. et Entomol. Hung., 47, 125-132.

Olaniran, O. A., Sudhakar, A., Drijfhout, F., Dublon, I., Hall, D., Hamilton, J. and Kirk, W. (2013): A male-predominant cuticular hydrocarbon, 7-methyltricosane, is used as a contact pheromone in the western flower thrips Frankliniella occidentalis. J. Chem. Ecol. 39, 559-568.

Payne, R. J. (1998): Gradually escalating fights and displays: the cumulative assessment model. Animal Behaviour 56, 651-662.

Reaney, L. T., Drayton, J. M. and Jennions, M. D. (2011): The role of body size and fighting experience in predicting contest behaviour in the black field cricket, Teleogryllus commodus. Behav. Ecol. Sociobiol. $65,217-225$.

Rutte, C., Taborsky, M. and Brinkhof, M. (2006): What sets the odds of winning and losing? Tren. Ecol. Evo. $21,16-21$.

Smith, J. M. (1982): Evolution and the Theory of Games. Cambridge University Press. USA, 64, pp. 41-45.

Stevenson, P. A. and Rillich, J. (2012): The decision to fight or flee-insights into underlying mechanism in crickets. Frontiersin Neuroscience, 6, 118.

Taylor, P. W., and Elwood, R. W. (2003): The mismeasure of animal contests. Animal Behaviour 65, 1195-1202.

Terry, L. I. (1995): Competition in western flower thrips males: effects of density on behaviour. In: B. L. Parker, M. Skinner and T. Lewis (eds): Thrips Biology and Management. Plenum Press, New York. pp. 433-438.

Terry, L. I. and Gardner, D. (1990): Male mating swarms in Frankliniella occidentalis (Thysanoptera: Thripidae). J. Insec. Behav. 3, 133-14.

Terry, L. I. and Dyreson, E. (1996): Behavior of Frankliniella occidentalis (Thysanoptera: Thripidae) within aggregations, and morphometric correlates of fighting behavior of Frankliniella occidentalis (Thysanoptera: Thripidae) within aggregations and morphometric correlates of fighting. Ann. Entom. Soc. 89, 589-602.

Thomas, M. L. and Simmons, L. W. (2009): Male dominance influences pheromone expression, ejaculate quality, and fertilization success in the Australian field cricket, Teleogryllus oceanicus. Behavioral Ecology, 20, 1118-1124.

West, S., Murray, M., Machado, C., Griffin, A. and Herre, E. (2001): Testing Hamilton's rule with competition between relatives. Nature 409, 510-513.

Whitehouse, M. E. (1997): Experience influences male-male contests in the spider, Argyrodes antipodiana (Theridiidae: Araneae). Animal Behaviour 53, 913-923.

Zhang, P. J., Zhu, X. Y. and LU, Y. B. (2011): Behavioural and chemical evidence of a male-produced aggregation pheromone in the flower thrips Frankliniella intonsa. Physiol. Entomol. 36, 317-320.

Open Access statement. This is an open-access article distributed under the terms of the Creative Commons Attribution 4.0 International License (https://creativecommons.org/licenses/by/4.0/), which permits unrestricted use, distribution, and reproduction in any medium, provided the original author and source are credited, a link to the CC License is provided, and changes - if any - are indicated. (SID_1) 